by Colonel Elliott and Captain Henry to be very strong. The parietal pleura should be sewn together if possible; if the opening is too large then it may be stitched to the lung and visceral pleura. The skin and muscle are brought together with a few interrupted sutures. Where the skin, however, cannot be elosed the wound should be firmly packed with gauze, a salt or paraffin pack, and strapped.

\section{After. Treatment.}

This depends on the progress of the case. The majority, where the ideal early operation can be carried out, should do very well and make an uninterrupted recovery. It is extraordinary how quickly a lung will expand after the pleura is closed. If much blood should collect it should be aspirated. If gas infection or empyema supervene the ordinary treatment shọuld be carried out and the pleural cavity drained. This can be done through the original wound if dependent; if not, a lower rib should be resected and the cavity drained.

Localized Collection.

A local collection of pus round the wound may develop and require evacuation.

Conclusions.

The ideal methods of modern war surgery are (1) early operation, (2) complete excision of wound and damaged tissues, (3) removal of metal fragment and clothing, (4) mechanical cleansing of wound (the use of strong antiseptics is to be avoided), (5) complete suture of wound. Provided one can get early and complete operation, there is far more danger from secondary than from primary infection.

The treatment of wounds of the chest; therefore, follows the same lines as those of the abdomen, head, knee, or other joints; they require just as early operation, and it will be found that the results are just as good.

\section{THE TREATMENT OF GUNSHOT WOUNDS OF THE ELBOW-JOINT : A PLEA FOR PRIMARY EXCISION.}

By C. MANSELL MOULLIN, F.R.C.S., LIEUT.-COLONEL R.A.M.C.(T.F.)

2ND LONDON (CITY OF LONDON) GENERAL Hospital.

ThE ultimate results of the injuries inflicted in gunshot wounds of the elboiv-joint cannot be regarded as satis. factory. In the majority there is complete, or almost complete, ankylosis. If the wound pursues a thoroughly aseptic course, and the injury is confined to the olecranon or one of the epicondyles, the joint may regain a fair range of movement. But when, as in the majority of instances, the wound becomes septic and the bones are badly comminuted, especially if the lower end of the humerus is involved, the results are deplorable. Effective drainage is very difficult to carry out, oven if CarrelDakin's method is employed. Acute septic inflammation nearly always follows. The whole region of the elbow becomes immensely swollen. Accurate reposition of the broken fragments is out of the question. A great deal of new bone is thrown out, many of the fragments become necrosed, and after a prolonged illness running into many months the elbow is left either ankylosed at an awkward angle, so that often the patient cannot use his hand to feed himself, or at best with - a limited degree of flexion and extension, with rotation at the shoulder-joint as a clumsy substitute for supination.

The results of primary excision of the elbow-joint, on the other hand, are wonderfully good, provided sufficient bone is removed-that is to say, the lower end of the humerus just above the level of the epicondyles, the whole of the head of the radius and the vlna at the sane- level. I have notes of five cases in civil practice-performed-for injury in which the joint was excised in this way, with complete restoration of movement and recovery of the muscles so that the arm was to all intents and purposes as strong and as useful as it was before. Even if the conditions are such that the wound is already infected; the drainage is so free that a serious degree of sepsis can usually be avoided, and there is not that enormous mass of callus thrown ont, binding everything together and locking the fragments so that they cannot move. It is true that, owing to the necessity of re-educating the muscles of the forearm, which have been separated from their attachments, it may be twelve months before recovery is complete, but the fingers and wrist can be used after the first few weeks, and, if a suitable splint is pro. vided, the elbow as soon as the wound is sound.

The operation, of course, is much more tedious when performed for injury than when performed for disease. The muscles cannot be so easily separated from their attachments, and when the bones are comminuted and the fragments displaced, there is need of careful dissection, which may take up valuable time. But provided the operation can be done before septic infection has spread far, and sufficient bone is removed, the results are so different from those of the conservative method of treat. ment that there is no comparison between them.

It is not, of course, possible to say whether the con-" ditions at a casualty clearing station are such as to allow a proceeding of this kind to be carried out at a time when every moment is required, but the only conclusion at which one can arrive from three years' experience at a base hospital, is that if primary excision of the elbow were adopted more generally a great deal of illness and suffering would be saved and much more useful limbs would be left. Excision can, of course, be performed later with an ex. cellent result, and doubtless in many cases it will be, but this means a second operation of some gravity and a second period of convalescence before recovery is complete.

\section{fftemoranda:}

\section{MEDICAL, SURGICAL, OBSTETRICAL.}

REAMPUTATION.

The following technique has been evolved in the Dartford War Hospital in the large number of reamputations per formed here. Various points were gleaned from various sources, and among the most valued recent suggestions is that of Major W. A. Chapple ${ }^{1}$ to employ button sutures of relaxation in the deeper parts of the flap.

Preliminary-During the-waiting period use a weight and pulley with adhesive plaster to bring down the skin. Clean up the surface as thoroughly as possible but do not wait for all small pockets to become healthy. A fortnight is long enough.

Stage 1.-Apply a tourniquet. Curette the whole surface, especially any pockets, whilst flushing thoroughly with a dilute antiseptic.

Stage 2.-(Usually needed but not always.) Make a free incision down to the bone on the outer side of the limb, exposing it to above the intended line of section.

Stage 3:- Make a circutar incision round the bone near its end, through the periosteum, above the point at which there are spurs and plates of new bony deposit; but where these extend up the shaft far, then at 1 in. from the surface of the stump. Carefully peel the tissues, including the periosteum, off the bone, splitting them through the outer incision.

Stage 4.-Cut the bone either with a Gigli saw, which we have been frequently employing for the past eighteen months, or by the ordinary saw if the tissues can be retracted sufficiently. Use a cloth retractor with a hole in it to slip over the end of the bone. I devised a special metal retractor but it did not work satisfactorily.

Stage 5.-Study the stump; see whether any of the fleshy mass needs to be trimmed to enable the skin to cover it. Free the skin from the underlying muscular tissues for $1 \frac{1}{2}$ in. to $2 \mathrm{in}$.; avoid scoring the subcutaneons fat.

Stage 6.- Remove the tourniquet; check all haemorrhage with ligatures and hot wet swabs.

Stage 7.-Suturing. Unite the periosteal sheath over the bone by a catgut mattress suture. Place two or three catgut sutures into the muscles, approximating them or inverting them as the case requires. Pnt in two or three silkworm-gut sutures, piercing rubber tabing in the way described by Major Chapple, compressing the flsps into gond spposition.

One small rubber drain should be placed from the deepest part by the bowe to the outer incision; another at the inner corner of the wound just under the skin flaps, which should be sutured at intervals of $\frac{3}{4}$ in. A yery usefal skin suture is often employed by my colleague, Mr. Bost. It pierces the skin in. from the edge then returns $\frac{1}{4}$ in. from the edge, which is thits stightly everted and closely apposed.

Since this technique lras been used (l) we have taken to eailier operation; (2) we lrave removed ratlier less bane; and (3) we have had better results in the way of primary waion.

1 Biritigh Medical Journal, August 25th, 1917, p. 242. 